

\title{
COLD VACUUM DRYING (CVD) ELECTRICAL EQUIPMENT (HYDROGEN) HAZARD PROTECTION
}

\author{
BL Philipp \\ COGEMA Engineering Corp. \\ Richland, WA 99352 \\ U.S. Department of Energy Contract DE-AC06-96RL13200
EDT/ECN: $628520 \quad$ UC:
Org Code: Charge Code: \\ B\&R Code: 39EW70400 Total Pages: 13
}

Key Words: CVD, Cold Vacuum Drying, SCIC, hydrogen, intrinsic safety

\begin{abstract}
This document explains that with the use of a helium purge and adequate control, the systems attached to the MCO in the CVDF are not in a flammable environment. Effective safeguards against ventilation failure are provided which reduces the flammability hazard classification within the protected enclosure to Unclassified. Intrinsically safe components are not required for this system.
\end{abstract}

TRADEMARK DISCLAIMER. Reference herein to any specific commercial product, process, or service by trade name, trademark, manufacturer, or otherwise, does not necessarily constitute or imply its endorsement, recommendation, or favoring by the United States Government or any agency thereof or its contractors or subcontractors.

Printed in the United States of America. To obtain copies of this document, contact: Document Control Services, P.O. Box 950, Mailstop H6-08, Richland WA 99352, Phone (509) 372-2420; Fax (509) 376-4989.

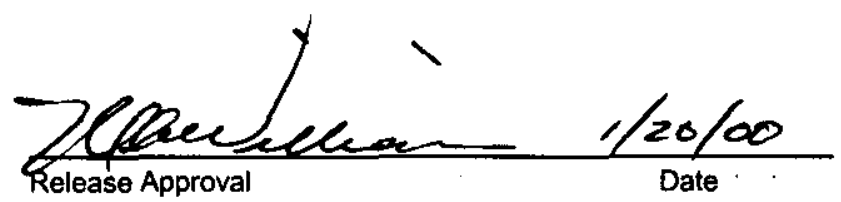

Approved For Public Release 


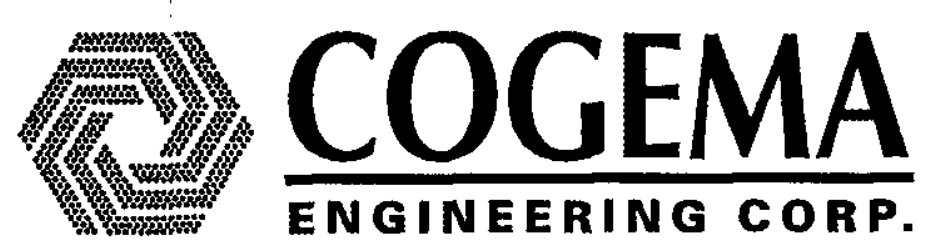

\section{COLD VACUUM DRYING (CVD) ELECTRICAL EQUIPMENT (HYDROGEN) HAZARD PROTECTION}

Babaik. Plilin

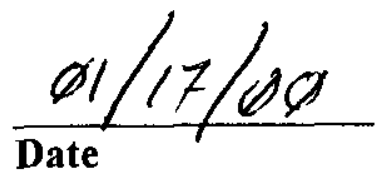

Electrical I\&C Engineering

COGEMA Engineering Corporation

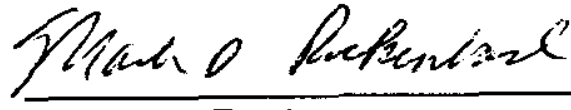

Technical Reviewer

Mark D. Rickenbach

Electrical 1 \& C Engineering

COGEMA Engineering Corporation $\frac{61 / 18 / 00}{\text { Date }}$ 
SNF-5100, Rev. 0

COLD VACUUM DRYING (CVD) ELECTRICAL EQUIPMENT (HYDROGEN) HAZARD PROTECTION

Prepared for

Fluor Hanford, Inc.

Richland, Washington

by

B. L. Philipp

COGEMA Engineering Corporation

Richland, Washington

January 2000 
SNF-5100, Rev. 0

TABLE OF CONTENTS

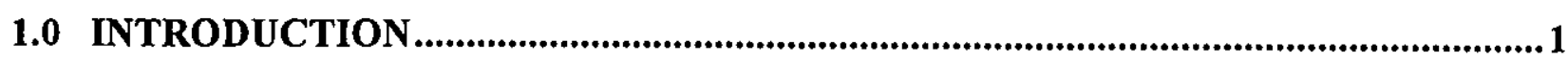

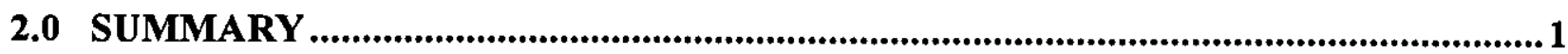

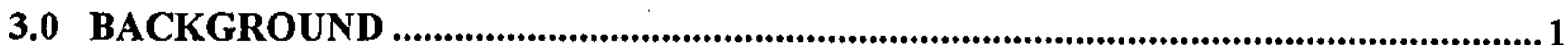

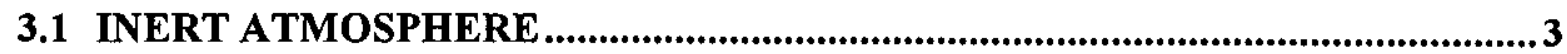

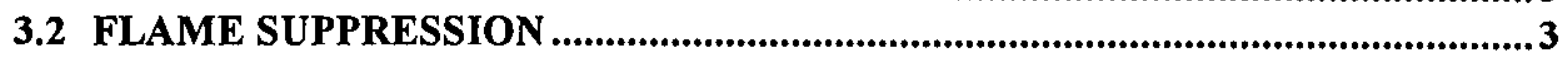

3.3 CLASSIFICATION USING TYPE X AND Z PURGE/PRESSURIZATION...........4

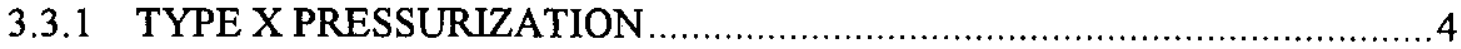

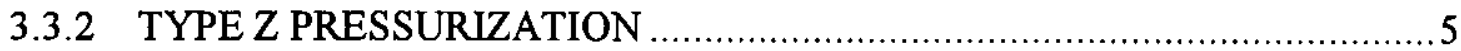

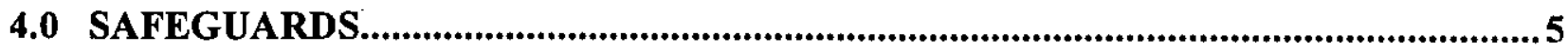

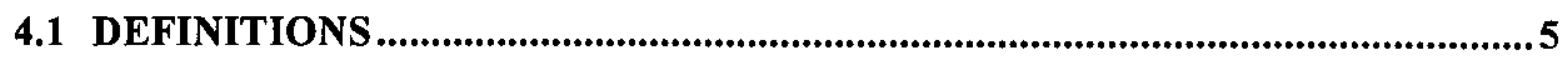

FIGURE 4-2. COLD VACUUM DRYING PROCESS CONNECTIONS AND

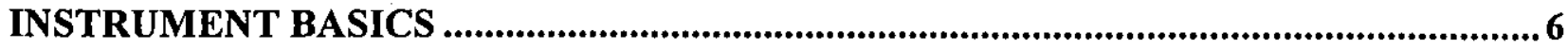

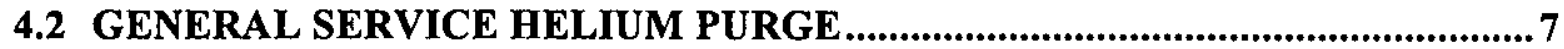

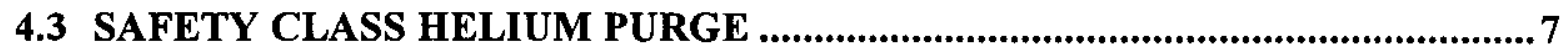

4.4 SAFETY CLASS INSTRUMENTATION AND CONTROL SYSTEM (SCIC) ....7

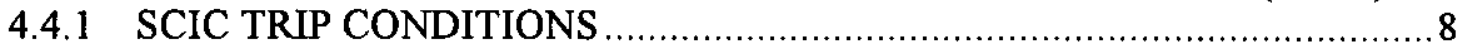

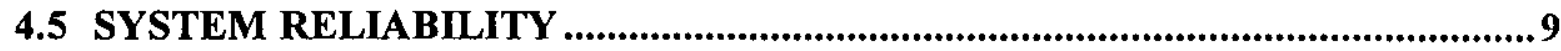

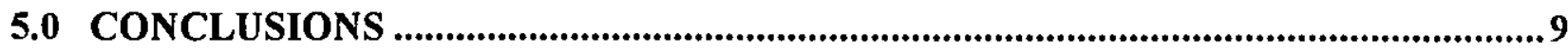

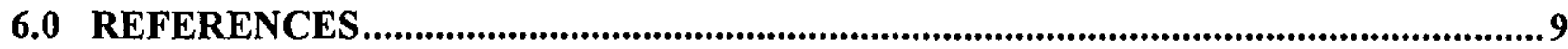

Table of Figures

Figure 4-2. Cold Vacuum Drying Process Connections and Instrument Basics ..........................6 
SNF-5100, Rev. 0

\section{COLD VACUUM DRYING (CVD) ELECTRICAL EQUIPMENT (HYDROGEN) HAZARD PROTECTION}

\subsection{INTRODUCTION}

The purpose of this document is to document the adequacy of the flammable gas (hydrogen) protections in place for the electrical equipment used within the Cold Vacuum Drying (CVD) process while the multi-canister overpack (MCO) is connected.

\subsection{SUMMARY}

With the use of a helium purge and adequate controls, the systems attached to the MCO are not in a flammable environment. Effective safeguards against ventilation (purge) failure are provided which reduces the classification within a protected enclosure from Class I, Division 2/Zone 2, to unclassified based on Type X Pressurization (isolated MCO) and Type Z Pressurization ${ }^{1}$.

The normal MCO process environment is an inert gas (helium). This environment consists of a general service helium $(\mathrm{He})$ purge to flush hydrogen from the system or to maintain positive pressure to preclude air (oxygen) ingress. Automatic safeguards are in place to initiate a safety-class helium ( $\mathrm{SCHe}$ ) purge and $\mathrm{MCO}$ isolation before hydrogen levels in the system can reach hazardous concentrations. Intrinsically safe components are not necessary for this system. Adding safeguards against purge failure has mitigated the flammability hazard. Note: the concept of intrinsic safety only applies to electrical equipment, not mechanical parts and thermal sources (MCO).

With no protections in place (i.e., a MCO connected to a system with an environment of helium), the Hazardous location classification for the CVD process would be defined as either Class I, Division 2, Group B (hydrogen) NFPA 70-1993 Article 500-5(b) or as Class I, Zone 2 $N F P A 496(1-4)$. A Division 2/Zone 2 location could have ignitable concentrations of hydrogen gas under normal conditions that are normally contained (separated from an oxygen source). Air (oxygen) ingress must be precluded because the MCO is a thermal source and could initiate an internal event. Only in the case of an accidental rupture or breakdown of the system can the hydrogen escape to the environment or can the system have oxygen ingress.

\subsection{BACKGROUND}

The vapor space in the MCO is a Class I, Division 2, Group B (hydrogen) location per NFPA 70-1993 Article 500-5(b), i.e., "A Class 1, Division 2 location is a location:

(1) in which volatile flammable liquids or flammable gases are handled, processed or used, but in which the liquids, vapors, or gases will normally be contained within closed containers or closed systems from which they can escape only in case of accidental rupture or breakdown of such containers or systems, or in case of abnormal operation of equipment; or

\footnotetext{
${ }^{1}$ NFPA 496-98 Standard for Purged and Pressurized Enclosures for Electrical Equipment
} 
(2) in which ignitable concentrations of gases or vapors are normally prevented by positive mechanical ventilation, and which might become hazardous through failure or abnormal operation of the ventilation equipment...". The potential exists that the hydrogen generated in the MCO vapor space could, in the presence of an oxidizing medium, be within the lower and upper flammability limits.

The National Electrical Code, NFPA 70-1993 Article 500-2 Location and General Requirements, states that " hazards may be reduced or hazardous (classified) location limited or eliminated by adequate positive-pressure ventilation from a source of clean air in conjunction with effective safeguards against ventilation failure". NFPA 70 does not go into detail on purged systems because it is primarily concerned with electrical systems and a purge is mechanical. The standard directs the reader to NFPA 496 for further information for hazard reduction. NFPA 496 (Chapter 6) requirements are being used to mitigate a potentially flammable gas hazard situation instead of NFPA 70 because of several reasons:

- Standard 496 chapter 6 applies to enclosed environments with an internal source of flammable gas, i.e., the MCO is generating the hydrogen gas.

- The MCO is a non-electrical spark source.

- Intrinsically safe equipment for a hydrogen hazardous gas environment is not always available and other techniques must be used.

Note: Where a release of flammable gas occurs within the enclosure under normal or abnormal conditions, NFPA 496 (6) includes the additional requirement of an inert purge gas to reduce oxygen content in the enclosure to less than 5 percent by volume.

Because the MCO generates hydrogen gas and no explosive reaction can be tolerated, inert atmospheres must be used. When the MCO is placed in the Cold Vacuum Drying Facility (CVDF) with a helium purge, the systems and associated piping can be regarded as nonclassified, even though NFPA 496 does not directly apply to non-electrical ignition sources such as the MCO. A fail-safe, above atmospheric pressure, He purge system is provided for normal operations, with safety-class Helium (SCHe) purge and Safety-Class Instrumentation and Control (SCIC) provided for safeguards during accident situations as a method for expelling any buildup of hydrogen from the MCO and associated piping. During all operational periods, the SCIC system monitors process parameters and will initiate the SCHe when required. For example, the SCIC monitors the following parameters: $\mathrm{MCO}$ pressure, length of time under vacuum, and time to reach a vacuum level (indicates potential inleakage of air). If a value exceeds the specified limits, the SCIC system will trip the safety-class isolation and system purge and return the MCO to a protected "safe" state. Because of the drying process, there are times that the system is under vacuum and the purge system is not utilized. During this time, hydrogen is limited by maintaining low vacuum pressure, with insignificant hydrogen to support combustion should an air leak occur. 


\subsection{INERT ATMOSPHERE}

Helium is the chosen inerting agent for the CVDF. In general, helium is less effective than nitrogen or carbon dioxide for inerting. However, helium is more effective for cooling, either for flame suppression (cools gas to below ignition temperature) or MCO fuel cooling. The cooling aspect makes it more effective than nitrogen or carbon dioxide for flame suppression in narrow piping (less than $2.2 \mathrm{~cm}$ diameter $^{2}$ ).

The addition of a chemically inert substance, helium, in the CVD process piping, MCO, and ventilation systems causes the upper and lower flammability limits of the gas to approach each other. Experiments using helium (worst case situation), have shown that the lowest hydrogen value that is flammable when mixed in air is $8.7 \% \mathrm{H}_{2}$ and $91.3 \% \mathrm{He}^{3}$. At atmospheric pressure, this mixture can support a flame when mixed with air. The upper and lower flammability limit for this blend is $69.8 \%{ }^{3}$ of the $\mathrm{H}_{2}-\mathrm{He}$ mixture in a balance of air. This means that the environment will become flammable if there is $8.7 \% \mathrm{H}_{2}$ in Helium in the MCO and a leak into the MCO occurs which allows the environment to become $30.2 \%$ air. Therefore, to protect from an explosion, the trip functions of the SCIC must purge and re-pressurize the system before hydrogen can accumulate to the lower flammability level $(8.7 \%)$.

\subsection{FLAME SUPPRESSION}

For intrinsically safe systems, both electrical and thermal energy must be limited to a level below the amount necessary to ignite the gas mixture's most easily ignitable concentration. The majority of equipment that is classified as intrinsically safe is only rated for gasses in Groups $\mathrm{C}$ and $\mathrm{D}$ categories because of the low ignition energy for Group $\mathrm{A}$ and $\mathrm{B}$.

(1) Group A (Acetylene - ignition energy $0.017 \mathrm{~mW} / \mathrm{s}$ )

(2) Group B (example Hydrogen - ignition energy $0.017 \mathrm{~mW} / \mathrm{s}$ ).

(3) Group C (example: Ethylene - ignition energy $0.08 \mathrm{~mW} / \mathrm{s}$ ) or

(4) Group D (example: Methane - ignition energy $0.3 \mathrm{~mW} / \mathrm{s}$ )

For cases where the electrical and thermal sources cannot be rendered intrinsically safe, flame suppression techniques (inerting gasses, restrictions, flame arrestors) can be used effectively. The minimum amount of energy necessary to ignite a hydrogen mixture and initiate combustion (deflagration) is $0.011 \mathrm{~mJ}^{5}$. Because of the low ignition energy, a hydrogen flame will burn through the restriction or flame arrestor. However, changing the gas mixture, i.e., through adding a sufficient amount of inert gas, can eliminate the gas ignition hazard. "Inert atmospheres must be used when not even a small explosive reaction can be tolerated." 6

${ }^{2} \mathrm{Pg} .5$ Coward, H. F., and G. W. Jones, Limits of Flammability of Gases and Vapors, Bureau of Mines Bulletin 503, United States Government Printing Office, Washington D.C., 1952.

${ }^{3}$ Pg. 22 Coward, H. F., and G. W. Jones, Limits of Flammability of Gases and Vapors.

${ }^{4}$ Svacina, B., Understanding Hazardous Area Sensing, TURCK, Inc, Minneapolis, Minnesota, 1994.

${ }^{5}$ Magison, E. C., Electrical Instruments in Hazardous Locations, 3rd Edition, Instrument Society of America, 1978 .

${ }^{6} \mathrm{Pg} .18$ Zabetakis, M. G., Flammability Characteristics of Combustible Gases and Vapors, Bureau of Mines Bulletin 627, United States Government Printing Office, Washington D. C., 1964, updated 1976. 


\subsection{CLASSIFICATION USING TYPE $X$ and $Z$ PURGE/PRESSURIZATION}

Based on NFPA 496-98 (1 -4) Standard for Purged and Pressurized Enclosures for Electrical Equipment, the CVD process environment is a Class I, Zone 2 location, i.e., A location

“...(2) in which volatile flammable liquids, flammable gases, or flammable vapors are handled, processed or used, but in which the liquids, gases, or vapors normally are confined within closed containers or closed systems from which they can escape only as the result of the abnormal operation of the equipment with which the liquids or gases are handled, processed, or used; or in which ignitable concentrations of flammable gases or vapors normally are prevented by positive mechanical ventilation, but which may become hazardous as a result of failure or abnormal operation of ventilation equipment; ..."

\subsubsection{TYPE X PRESSURIZATION}

Type X Pressurization is used for protecting the MCO for safety considerations, even though the MCO is included as part of the Class 1, Division 2/Zone 2 environment. A Type X purge is typically used for Class 1 Division 1/Zone 1 environments that contain a source of ignition (such as the fuel in the $\mathrm{MCO}$ ) and contain a source of flammable gas during normal operations. This type of purge provides the most protection and alarms, and can be used to reduce classification for electrical equipment requirements from a Division 1 location to a nonhazardous location.

The elements that constitute a Type $\mathrm{X}$ purge/pressurization system include the basic requirements for a pressurized enclosure, such as:

(1) Constructed from material that is not likely to be damaged under normal conditions

All piping, valves, and equipment that are a portion of the CVD system pressure boundary are rated to $150 \mathrm{lb} / \mathrm{in}^{2}$ gauge.

(2) Precautions provided to protect the enclosure from excess pressure

A safety-class system consisting of a rupture disk and check valve is installed in the short process tube process connector to provide protection from overpressurization of the MCO. The $30 \mathrm{lb} / \mathrm{in}^{2}$ gauge vent path is used as a backup to the SCHe system vent path to ensure the pressure will not reach the MCO $150 \mathrm{lb} / \mathrm{in}^{2}$ gauge rupture disc rating.

as well as alarms and a cut-off switch, such as:

(3) Alarms in a constantly attended location

The SCIC provides safety class alarms to the CVDF control room such as low water level in the Cask/MCO annulus, activation of the SCIC MCO isolation and SCHe system purge (ISO\&PURGE), and PWC Purge failures. The SCIC system also provides 


\section{SNF-5100, Rev. 0}

non-safety-class signals to the facility Monitoring and Control System (MCS) for normal control, indication, and alarms. The signals from the SCIC include all analog signals (flow and pressure), SCIC internal logic trip, alarm contact status and seismic trip contacts.

(4) A cutoff switch to de-energize power automatically (flow or pressure actuated) from all electrical elements not approved for Division 1/Zone 1 upon failure of the protective gas supply (or other trip situations)

Under normal conditions, the MCS controls all eight MCO isolation valves. The SCIC system will automatically isolate MCO (spark source and flammable gas source) and initiate the $\mathrm{SCHe}$ purge during process upset conditions. The portions of any equipment within the gas stream inside the isolation boundary do not contain any spark sources and do not need to be deenergized.

\subsubsection{TYPE Z PRESSURIZATION}

The balance of the CVD piping and process systems outside of the isolation boundary is protected (flammable gas) using Type $Z$ Purge/Pressurization. Type $Z$ purge/pressurization can be used to reduce a Class I, Division 2/Zone 2 location within a protected enclosure with no flammable gas under normal conditions to unclassified. With Type $Z$ purging, a hazard is created only if the purge/pressurization system fails at the same time that a normally nonhazardous area becomes hazardous. For this reason, it is not considered necessary to remove power from equipment.

The general requirements for a Type $\mathrm{Z}$ pressurized system include the basic requirements for a pressurized enclosure (see Section 3.3.1 above), as well as alarms, such as the following:

Safety Class Alarms in CVD Control room - activation of the SCIC MCO isolation and SCHe system purge, and PWC Purge failure alarms.

\subsection{SAFEGUARDS}

For the following discussions, see Figure 4-1.

\subsection{DEFINITIONS}

ISO \& PURGE TRIP: This action is a result of contacts opening in the SCIC to deenergize the eight $\mathrm{MCO}$ isolation valves and four $\mathrm{SCHe}$ isolation valves. Since the eight valves are fail-closed, the MCO is isolated from the general service and non-seismically qualified portions of the process systems: the Vacuum Purge System (VPS) (System 07), the He system (System 13-1), and the Process Water Conditioning (PWC) System (System 46). The SCHe purge is enabled when the SCHe valves are de-energized open (fail-open on loss of power). This opens two valves on the long dip tube process connector and two on the short dip tube side.

PWC LOW FLOW: This alarm signifies that, during the PWC pre-purge or post-purge, either there was a low-flow rate or the minimum time for the purge was not met. 
Figure 4-1. Cold Vacuum Drying Process Connections and Instrument Basics

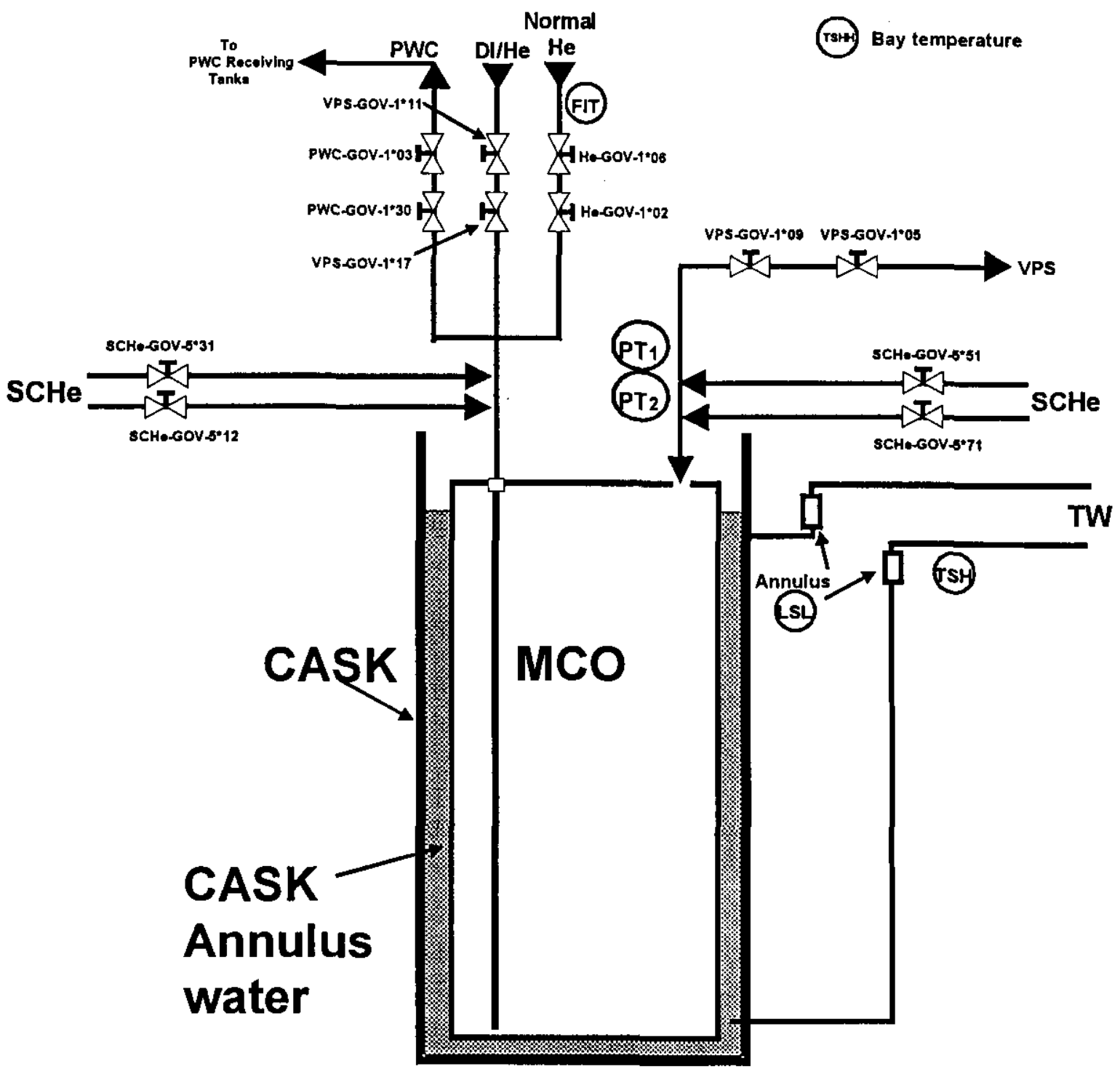

Note: All Instruments, PT, FIT, TSH and LSL have two components per bay.

PT1: Pressure Transmitter (PT 1*36, 1*37)

PT2: Pressure Transmitter (Vacuum) (PT 1*08, 1*10)

FIT: Flow Indicating TransmItter (FIT 1*20, 1*21)

TSH: Temperature Switch High (TSH 1*28, 1*29)

LSL: Level Switch Low (LSL 1*24, 1*25)

TSHH: Bay Temperature Switch High High (TSHH 1*38, 1*39)

Note: The * represents 2 through 5 for bays 2 - 5 


\subsection{GENERAL SERVICE HELIUM PURGE}

The He system is a general service inert gas purging system that contains safety-class components required to ensure the safe operation of the CVDF. The Monitoring and Control System (MCS) monitors He system parameters and provides process control signals. The $\mathrm{He}$ purge flow rate is a safety-class input to the SCIC system.

During normal operations the He system provides helium for purging the cask headspace before removing the cask lid, purging the VPS and MCO prior to draining, backfilling the MCO headspace during draining, purging the MCO during vacuum dying, and backfilling the MCO and the cask annulus at the completion of CVDF processing. It also provides helium for purging VPS equipment and for purging PWC lines and tanks, as well as for leak testing valves and process seals. Following a SCIC actuation (MCO isolation and purge trip), the He system can supply helium to the SCHe if the He system was not affected by the event causing the SCIC actuation.

\subsection{SAFETY CLASS HELIUM PURGE}

The SCHe system is a dedicated safety-class, inert gas purge system that can be actuated automatically by a SCIC signal in response to predetermined process parameter setpoints, a seismic event, or manually via buttons in the control room or in the bay. Due to its fail-safe design, the SCHe system will also be initiated if there is a loss of control air or if power is lost to the valves or the SCIC system. The essential function of the SCHe system is to purge and pressurize the MCO with helium, and to provide a ventilation path following a system trip to the local exhaust system.

Each process bay has its own redundant SCHe system. Two separate locations are provided for the SCHe bottle storage and SCHe equipment panels in each bay.

\subsection{SAFETY CLASS INSTRUMENTATION AND CONTROL SYSTEM (SCIC)}

The SCIC system provides safety sensing, actuation logic, actuation signals, and control interfaces to prevent a MCO fuel runaway reaction (over temperature and pressure blowdown) or a hydrogen explosion within the MCO. Additional features provide protection from both external hydrogen explosion and spray leak accidents, i.e., (1) SCIC detection of process upset or (2) bay temperature detection. Both are used to initiate a process shutdown using isolation and purge.

The SCIC system provides active detection and response to process anomalies that, if unmitigated, could result in unacceptable consequences. To perform these functions, the SCIC system monitors process parameters, detects off-normal conditions, and actuates relays to de-energize the $\mathrm{MCO}$ isolation valves, $\mathrm{SCHe}$ isolation valves, and tempered water heater.

The SCIC system is a fully automatic system that requires no operator action to detect and respond to process upsets within the process parameters that the SCIC controls. The SCIC system provides safety-class alarms to the CVDF control room for those events that require operator actions, including MCO isolation and purge (ISO \& PURGE) and ANNULUS LOW LEVEL. 


\subsubsection{SCIC TRIP CONDITIONS}

The SCIC system isolates the $\mathrm{MCO}$ and initiates a $\mathrm{SCHe}$ system purge if any of the following occur:

- Loss of power (fail-safe condition)

- Manually-initiated safety-class isolation and SCHe purge from one of the SCIC ISO \& PURGE buttons (administratively-controlled)

- $\quad$ Exceeding eight hours at vacuum during the first vacuum cycle or four hours of vacuum during all subsequent vacuum cycles without re-pressurizing the MCO for a minimum of four hours. This is referred to as the $8 / 4 / 4$ requirement and provides thermal reset within the MCO

- $\quad$ MCO below atmospheric pressure and the helium flow below the minimum required to keep hydrogen less than $8 \%$ in He by volume. When MCO total pressure is below 12 torr, there is insufficient hydrogen to exceed the $8 \%$ level and no purge is required. Note that even for hydrogen in air mixtures, no mixture below 50 torr will propagate a flame ${ }^{7}$. A five-minute time delay on low-flow allows flow to be stopped in order to reach $<12$ torr. In addition, after the 12 torr is achieved, a two-minute delay is provided to re-establish normal flow without a false trip condition

- $\quad$ MCO above the high-pressure setpoint

- The transition from above atmosphere SCIC actuation point $(0.5 \mathrm{psig})$ to vacuum, time to reach less than $-11.7 \mathrm{psig}(\sim 155$ torr $)$ exceeds five minutes

- The transition from below $-11.1 \mathrm{psig}(\sim 185$ torr $)$ back to greater than $0.5 \mathrm{psig}$ pressure exceeds five minutes

- $\quad$ MCO reaches an incorrect pressure state without adequate, verified purge volume. The MCO must be maintained above a positive pressure (approximately $0.5 \mathrm{psig}$ ) to prevent oxygen ingress unless a purge of adequate volume has been completed. During bulk water draining and the subsequence rinse, the $\mathrm{MCO}$ must remain above atmospheric pressure

- Bay temperature exceeds the high-temperature parameter limit of $105^{\circ} \mathrm{F}$, which impacts safety-class instrument calibration

- Seismic event of sufficient magnitude (below Uniform Building Code levels)

${ }^{7}$ Coward, H. F., and G. W. Jones, Limits of Flammability of Gases and Vapors, Bureau of Mines Bulletin 503, United States Government Printing Office, Washington D.C., 1952. 


\subsection{SYSTEM RELIABILITY}

The SCIC system requires that two SCIC safety-class trains monitor each process bay. This includes the portion that contains the MCO ISO \& PURGE trip, the tempered water trip, and the seismic monitoring trip. Each has two independent systems that are capable of independent action to perform their respective safety feature. All signals are through redundant transmitters or switches and all critical shutoffs are provided by at least two independent isolation valves for the ISO \& PURGE trip and two independent starters for the tempered water heater for the trin. The valves and tempered water heater are designed to fail-safe in the event of loss of power or, in the case of the isolation valves, loss of instrument air.

SCHe system purge is accomplished by two separate supply systems with two parallel purge valves in each system. These valves are designed to open on failure or loss of power.

\subsection{CONCLUSIONS}

The CVD process piping, $\mathrm{MCO}$, and ventilation systems is classified as a Class I, Division 2, Group B hazardous environment. However, by incorporating "effective safeguards against ventilation failure" (NFPA 70-1993 Article 500-2) the hazard has been reduced or eliminated. The requirements for Type X Pressurization are used near the MCO (ignition source and flammable gas source) and the requirements for Type $Z$ pressurization are used for the balance of the system (NFPA 496). All situations where hydrogen is known to accumulate during normal operations are mitigated with limiting time for hydrogen accumulation, providing a positive pressure purge, or maintaining an above atmospheric pressure in the MCO. Accident conditions automatically initiate an MCO ISO \& PURGE, which mitigates the situation with a positive pressure purge. Alarms are provided to a continuously staffed control room for offnormal notification.

\subsection{REFERENCES}

NFPA 496-98 Standard for Purged and Pressurized Enclosures for Electrical Equipment.

Coward, H. F., and G. W. Jones, Limits of Flammability of Gases and Vapors, Bureau of Mines Bulletin 503, United States Government Printing Office, Washington D.C., 1952.

Svacina, B., Understanding Hazardous Area Sensing, TURCK, Inc, Minneapolis, Minnesota, 1994.

Magison, E. C., Electrical Instruments in Hazardous Locations, 3rd Edition, Instrument Society of America, 1978.

Zabetakis, M. G., Flammability Characteristics of Combustible Gases and Vapors, Bureau of Mines Bulletin 627, United States Government Printing Office, Washington D. C., 1964, updated 1976.

Broschka, G. L., et al., A Study of Flame Arrestors in Piping Systems, Plant/Operations Progress, Vol. 2, No. 1, January 1983, pp. 5-12. 